\title{
Covid-19: Side Effects on Orthopaedic Patients
}

ISSN: 2576-8875

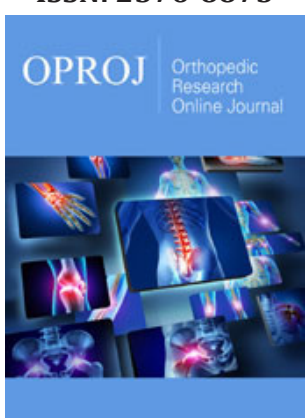

*Corresponding author: Michelangelo Palco, Department of Biomedical, Dental and Morphological and Functional Images, Section of Orthopaedic and Traumatology, University of Messina, Messina, Italy

Submission: 眥 June 21, 2021

Published: 醋July 06, 2021

Volume 8 - Issue 3

How to cite this article: Michelangelo Palco, Alito Angelo, Antongiulio Bruschetta, Demetrio Milardi, Danilo Leonetti. Covid-19: Side Effects on Orthopaedic Patients. Ortho Res Online J. 8(3). OPROJ. 000687. 2021.

DOI: 10.31031/OPROJ.2021.08.000687

Copyright@: Michelangelo Palco, This article is distributed under the terms of the Creative Commons Attribution 4.0 International License, which permits unrestricted use and redistribution provided that the original author and source are credited.

\author{
Michelangelo Palco ${ }^{*}$, Alito Angelo $^{2}$, Antongiulio Bruschetta ${ }^{3}$, Demetrio \\ Milardi ${ }^{1}$ and Danilo Leonetti ${ }^{1}$ \\ ${ }^{1}$ Department of Biomedical, Dental and Morphological and Functional Images, Section of \\ Orthopaedic and Traumatology, University of Messina, Messina, Italy \\ ${ }^{2}$ U.O.C of Physical and Rehabilitation Medicine and Sports Medicine, Italy \\ ${ }^{3}$ Orthopaedic Institute of Southern Italy, Franco Scalabrino, Italy
}

\begin{abstract}
Background: 11 March 2020 WHO declares the state of emergency due to Coronavirus disease. All governments take urgent aggressive actions including general lockdown to control disease transmission. The orthopaedic elective surgery activities have been stopped as result of limitation of hospital admissions. So, several patients waiting for surgery, have seen their procedure cancelled or postponed. In addition, few patients were warried about their surgery, or their outpatient visits due to fear of contracting Covid-19. In this particular historical period, we have seen consequences of this delay of treatments especially in untreated surgery complications and surgery rehabilitation programs.
\end{abstract}

Case series: three patients; one of these has been treated with delay, one has not been treated and one didn't get appropriate physical rehabilitation as a consequence of Covid-19 pandemic, in Sicily.

Conclusion: delay of treatments or avoided cares for treatable condition are side effect of Covid-19 pandemic, potentially dangerous like the direct consequences of the pandemic.

Keywords: COVID-19; Orthopaedics; Rehabilitation medicine; Physiotherapy; Orthopaedic and trauma surgery

Abbreviations: WHO: World Health Organization; Covid-19: Coronavirus Disease 2019; PFNA: Proximal Femoral Nail Antirotation; CoVs: Coronaviruses; SARS-Cov: Severe Acute Respiratory Sindrome; MERSCov: Middle East Respiratory Syndrome

\section{Introduction}

The year 2020 was characterized by the declaration by WHO (World Health Organization) of Coronavirus disease 2019 (Covid-19) pandemic which called all governments to take urgent aggressive action [1]. Many countries were forced to put themselves in lockdown with the aim to control the transmission of disease [2-9]. In this scenario, orthopaedic elective surgery and programmed outpatient visits have been stopped to avoid overloading and limit admissions in hospitals. At the time of the resume of elective surgery, it was estimated that in the United Kingdom were cancelled about 516000 orthopaedic procedures [10]. Actually, a lot of patients waiting for elective surgery are apprehensive about their surgery due to fear of contracting Covid-19. On the other hand, it is impossible to know how many patients would prefer to delay their treatments until after the end of this pandemic. According to a report by Johns Hopkins University updated to 1 January, 2021 the confirmed cases worldwide of Covid-19 were about 84,052 millions, with a total of 1,829 million of deaths [11].

Aim of this study is to show an emblematic case series of orthopaedic patients treated in Sicily (Southern Italy) with considerable delay, and patients who didn't get appropriate physical rehabilitation, as a consequence of Covid-19 pandemic. 


\section{Clinical Cases}

\section{Case report 1}

The patient was a 68 years old male, who had a car accident (Table 1). When he was admitted to the hospital, X-ray examination revealed a fracture of the surgical neck of left humerus and a fracture of the right femoral neck. He was treated with an intramedullary nailing of the femur (Proximal Femoral Nail Antirotation - PFNA system by ${ }^{\circledR}$ DePuy Synthes) (Figure 1). The humerus fracture was managed conservatively with a shoulder immobilization for the first two weeks. The patient had an uneventful postoperative period, and he began immediately postoperative rehabilitation without weight bearing for the first two weeks. He continued his rehabilitation program in the following months, after hospital discharge, in a physiotherapy centre near his home. He placed on him from the third week, and two weeks later he has recovered to walk by himself, with the help of two crutches. At 6 months of follow-up, the Physicians (M.P., D.L.) noted a delayed healing of the fractures on X-ray (Figure 2), despite the good clinical condition of the patient, in fact he had no pain, and he was able to walk by himself without crutches or a limp. In addition, the patient missed the one-year follow-up due to pandemic emergency in March 2020. Two months after, he developed groin pain of the right hip and it was treated with a phone consultation by his general practitioner for a sciatic problem. Because of the persistent pain he called his surgeon who prescribed a new X-ray that revealed a superomedial migration of the proximal femoral blade, a phenomenon called cutin [12] (Figures $3 \& 4$ ). For this reason, the patient underwent a primary total hip arthroplasty with stem revision ( $\odot$ Lima Corporate) in October 2020 (Figure 5).

Table 1: Timeline table.

Relevant Past Medical History and Interventions

Case Report 1. The Patient was a 68-Year-0ld Male, who had a Car Accident.

\begin{tabular}{|c|c|c|c|}
\hline Date & $\begin{array}{l}\text { Summaries from Initial and Follow-up } \\
\text { Visits }\end{array}$ & Diagnostic Testing & Interventions \\
\hline March 2019 & $\begin{array}{l}\text { Left humeral surgical neck fracture and } \\
\text { femoral neck fracture }\end{array}$ & $\begin{array}{l}\text { Radiographs of the humerus and of } \\
\text { the femur }\end{array}$ & $\begin{array}{l}\text { Intramedullary nailing of the femur, } \\
\text { discharges of hospital and begin of } \\
\text { rehabilitation }\end{array}$ \\
\hline April 2019 & Follow-up visits: • Walk by himself & Radiographs of the femur & Physiotherapy \\
\hline September 2019 & Follow-up visits: • Wellness & Radiographs of the femur & - \\
\hline March 2020 & Follow-up visits: missed & - & - \\
\hline May 2020 & $\begin{array}{l}\text { Follow-up visits (phone consultation): } \\
\text { groin pain and right limp }\end{array}$ & Radiographs of the femur & Scheduled for total hip replacement \\
\hline October 2020 & Total hip replacement & - & - \\
\hline
\end{tabular}

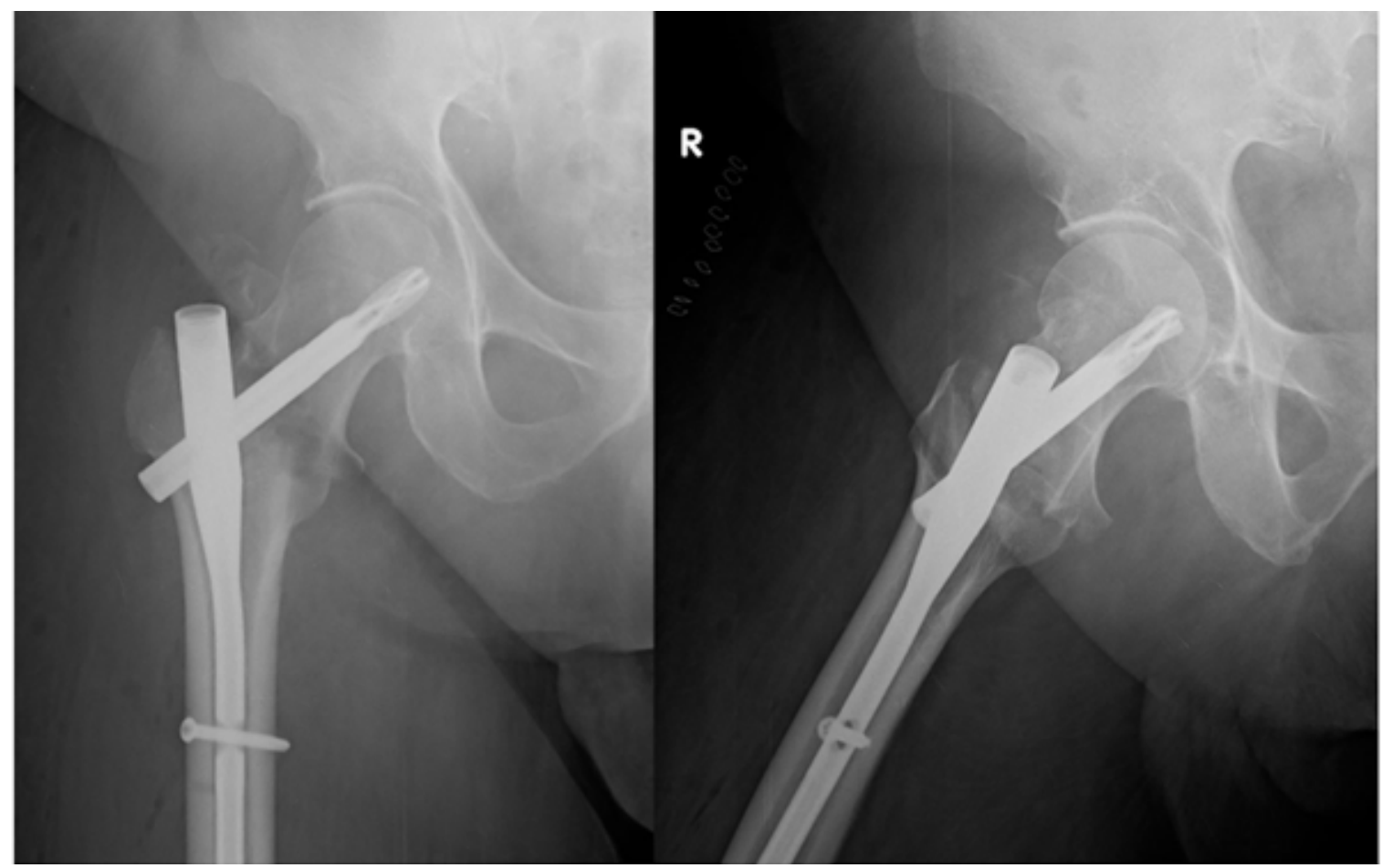

Figure 1: X-ray post-operative control. 


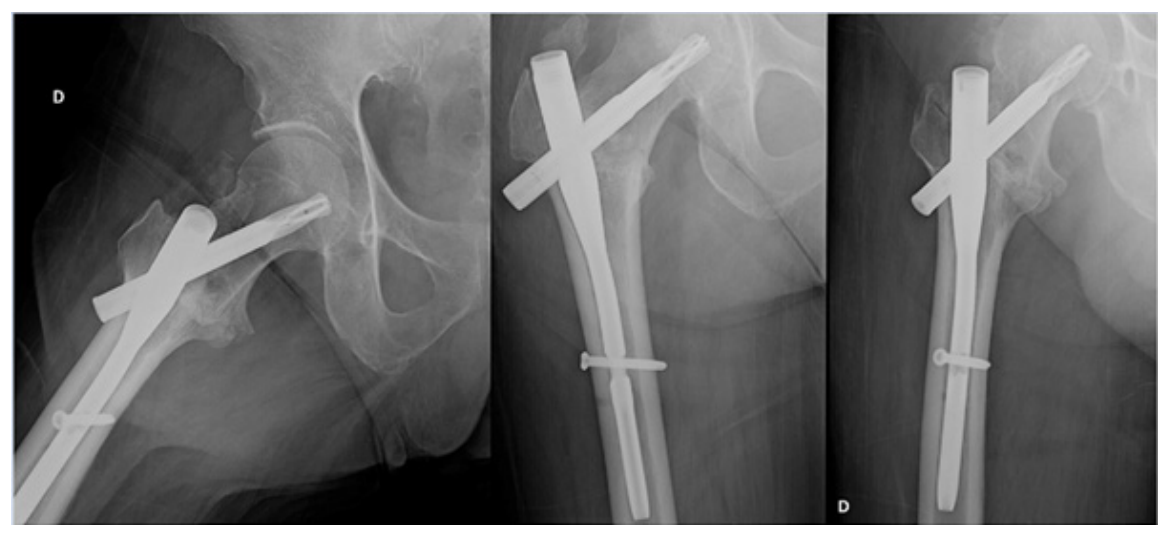

Figure 2: Six months follow-up X-ray control.

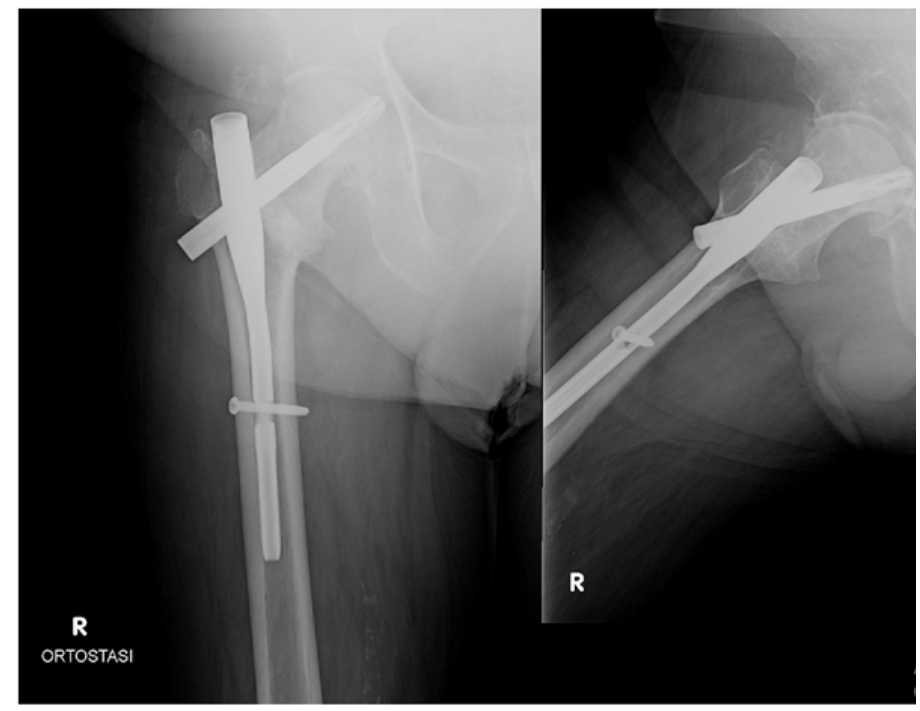

Figure 3: X-ray fourteen months after surgery and cut-in phenomenon.

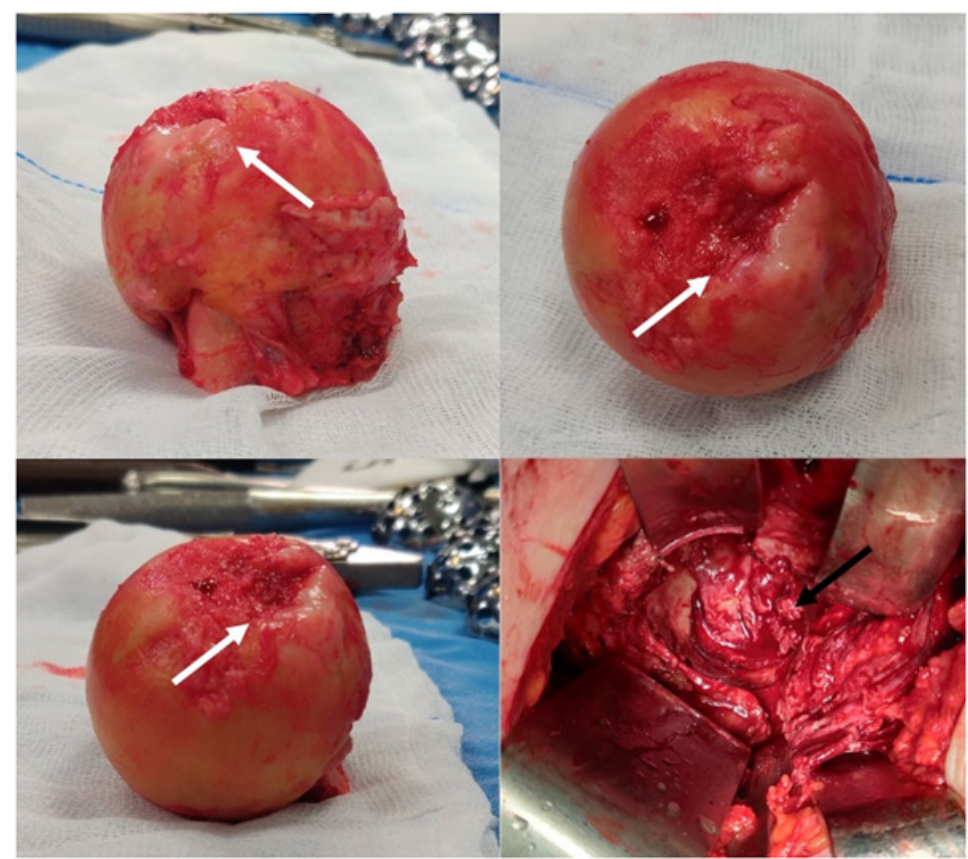

Figure 4: Intraoperative pictures: cut-in phenomenon (white arrow) and its sign on acetabulum (black arrow). 


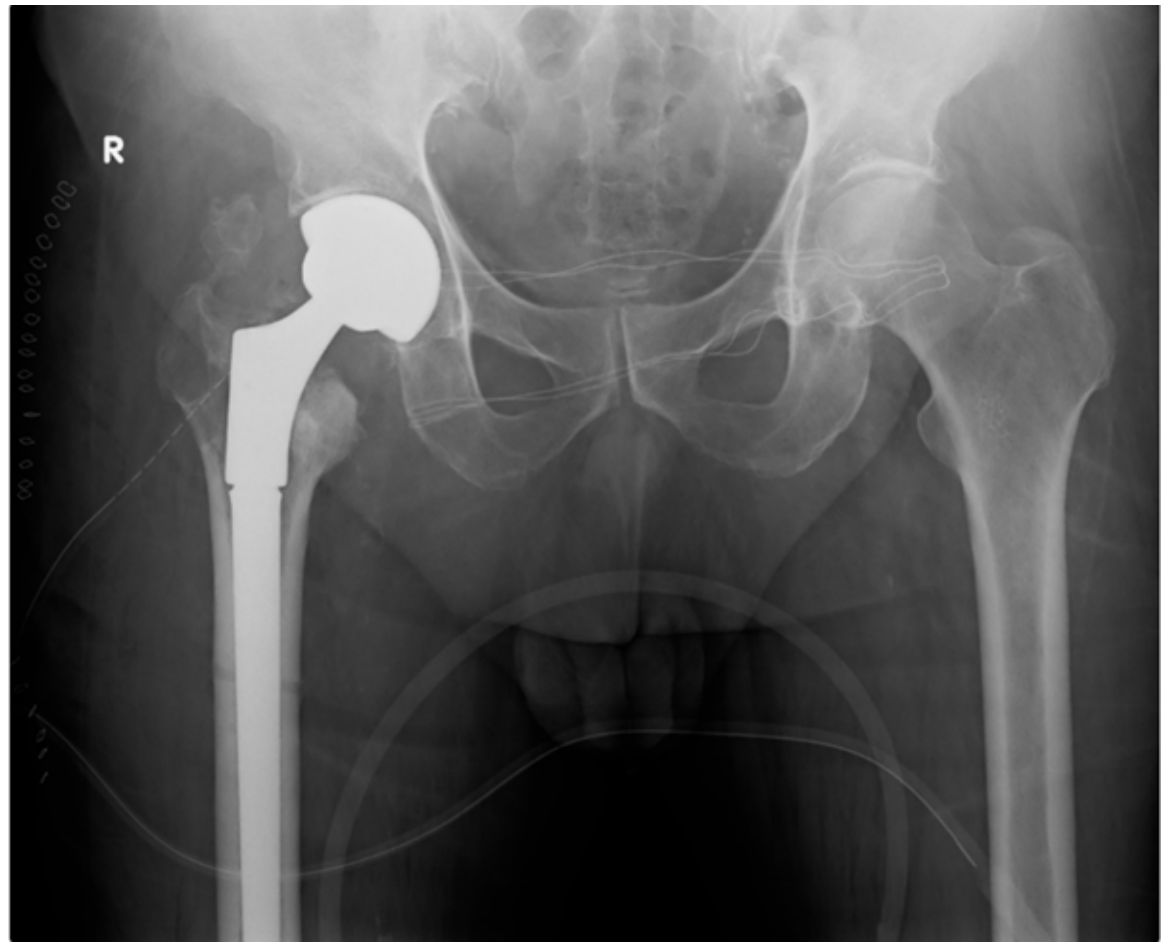

Figure 5: X-ray postoperative control.

\section{Case report 2}

The patient was a female of 58 years old, who had right chronic hip pain (Table 2) due to hip osteoarthritis treated for many years with medicines and intrarticular injections of corticosteroids first and then of hyaluronic acid. In November of 2019 she was scheduled for total hip replacement by her Physicians (M.P, D.L.) and 3 months after she underwent to surgery (primary total hip arthroplasty, Adler Ortho®) (Figure 6). She had an uneventful postoperative period where she started postoperative rehabilitation and she was formally discharged from hospital after four days. She continued her rehabilitation program until the closure of physiotherapy centres due to the general Italian lockdown, on 9 March of 2020. The patient missed several postoperative check-ups because of Covid-19 pandemic. In July 2020 she called her general practitioner for difficulty walking without crutches, even after a short ride, and she was referred to her surgeons. After 5 months, the surgeon noticed a Trendelenburg's sign positive, probably caused by gluteal muscles weakness with a waddling gate. Now the patient is following a strict home rehabilitation program prescribed by physiatrist to reinforce gluteal muscles (A.A).

Table 2: Timeline table.

\begin{tabular}{|c|c|c|c|}
\hline \multicolumn{4}{|c|}{ Relevant Past Medical History and Interventions } \\
\hline Date & $\begin{array}{l}\text { Summaries from Initial and Follow-up } \\
\text { Visits }\end{array}$ & Diagnostic Testing & Interventions \\
\hline September 2019 & Right chronic hip pain & Radiographs of the hip & $\begin{array}{l}\text { Medications, intrarticular injections } \\
\text { and rehabilitation }\end{array}$ \\
\hline November 2019 & $\begin{array}{c}\text { Follow-up visits: } \bullet \text { No improvement } \\
\bullet \text { Limp }\end{array}$ & & Scheduled for total hip replacement \\
\hline February 2020 & Total hip replacement & Radiographs of the femur & $\begin{array}{l}\text { Discharge from hospital, begin } \\
\text { rehabilitation program }\end{array}$ \\
\hline March 2020 & Follow-up visits: missed & - & - \\
\hline April 2020 & Follow-up visits: missed & - & - \\
\hline July 2020 & $\begin{array}{l}\text { Follow-up visits (phone consultation): } \\
\text { difficulty walking without crutches }\end{array}$ & - & - \\
\hline September 2020 & $\begin{array}{l}\text { Follow-up visits: } \\
\text { - Trendelenburg's sign positive } \\
\text { • Limp }\end{array}$ & - & Home rehabilitation program \\
\hline
\end{tabular}




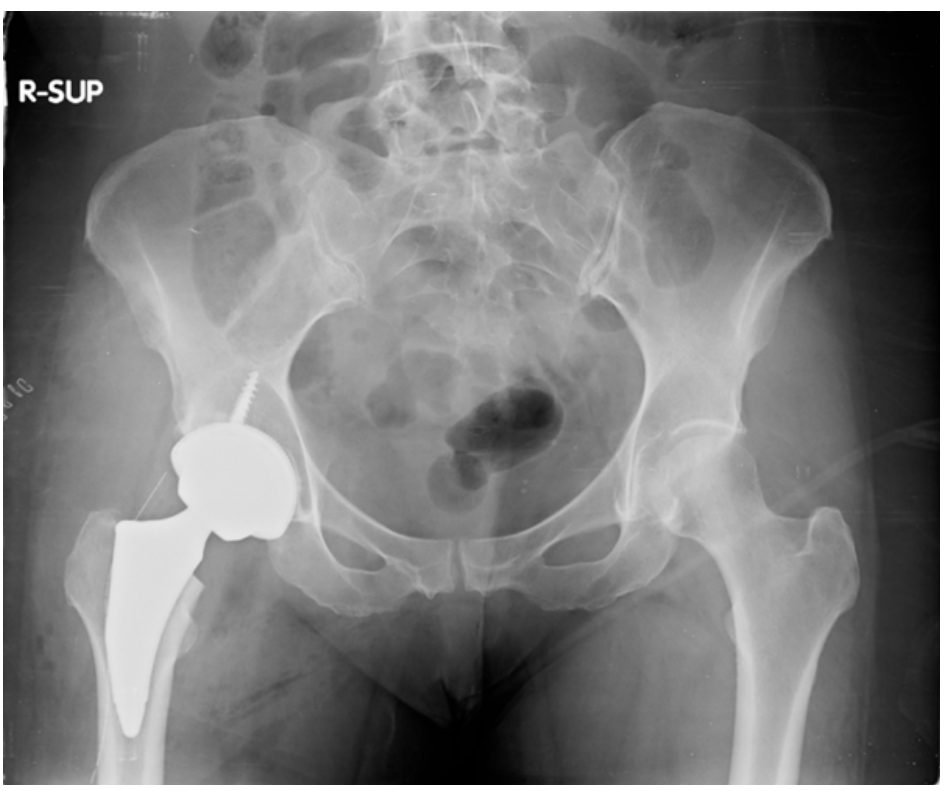

Figure 6: Total hip replacement on X-ray postoperative control.

\section{Case report 3}

The patient was a 56 years old male, who felt down on the floor with the arms thrown back in July 2019 (Table 3). During this event he also smacked his head against a table, suffering head trauma. In following months, he developed right shoulder pain and, in January of 2020, he was referred by his Physician (D.M.) to an orthopaedic surgeon (D.L., M.P.). MRI revealed a massive rupture of rotator cuff and the patient was scheduled to undergo arthroscopy on March 2020 for primary repair (Figure 7). However, due to Covid-19 restrictions in that period, surgery was postponed until June of 2020. and then was further delayed because patient was afraid to be infected by Covid-19 in hospital. Patient withdrew also from rehabilitation treatment for the same reason. An MRI carried out in December of 2020 revealed a total rupture of tendon of the long head of the biceps brachii and limited range of motion of the right shoulder (photos taken and sent to Physician by patient's son, Figure 8).

Table 3: Timeline table.

Relevant Past Medical History and Interventions

Case Report 3. The Patient was a 56-Year-Old Male, who Felt Down on the Floor with the Arms thrown Back in July 2019.

\begin{tabular}{|c|c|c|c|}
\hline Date & $\begin{array}{c}\text { Summaries from Initial and } \\
\text { Follow-up Visits }\end{array}$ & Diagnostic Testing & Interventions \\
\hline January 2020 & Right shoulder pain & MRI & $\begin{array}{c}\text { Scheduled for primary } \\
\text { arthroscopically repair (postponed } \\
\text { to June 2020) }\end{array}$ \\
\hline June 2020 & $\begin{array}{c}\text { Follow-up visits: missed Surgery: } \\
\text { refused by patient }\end{array}$ & $\begin{array}{c}\text { Rehabilitation program (refused by } \\
\text { patient) }\end{array}$ \\
\hline December 2020 & $\begin{array}{c}\text { No improvement, severe limitation } \\
\text { of ROM }\end{array}$ & MRI & Rehabilitation program \\
\hline
\end{tabular}

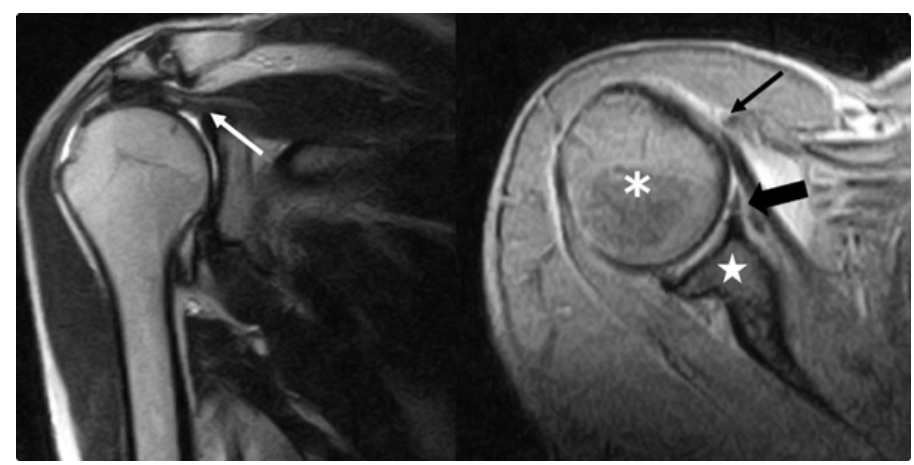

Figure 7: Signs of lesions on MRI; white arrow: supraspinatus tendon lesion; asterisk: humeral head; star: scapula; small black arrow: subscapular tendon lesion; fat black arrow: anterior glenoid labbrum lesion. 


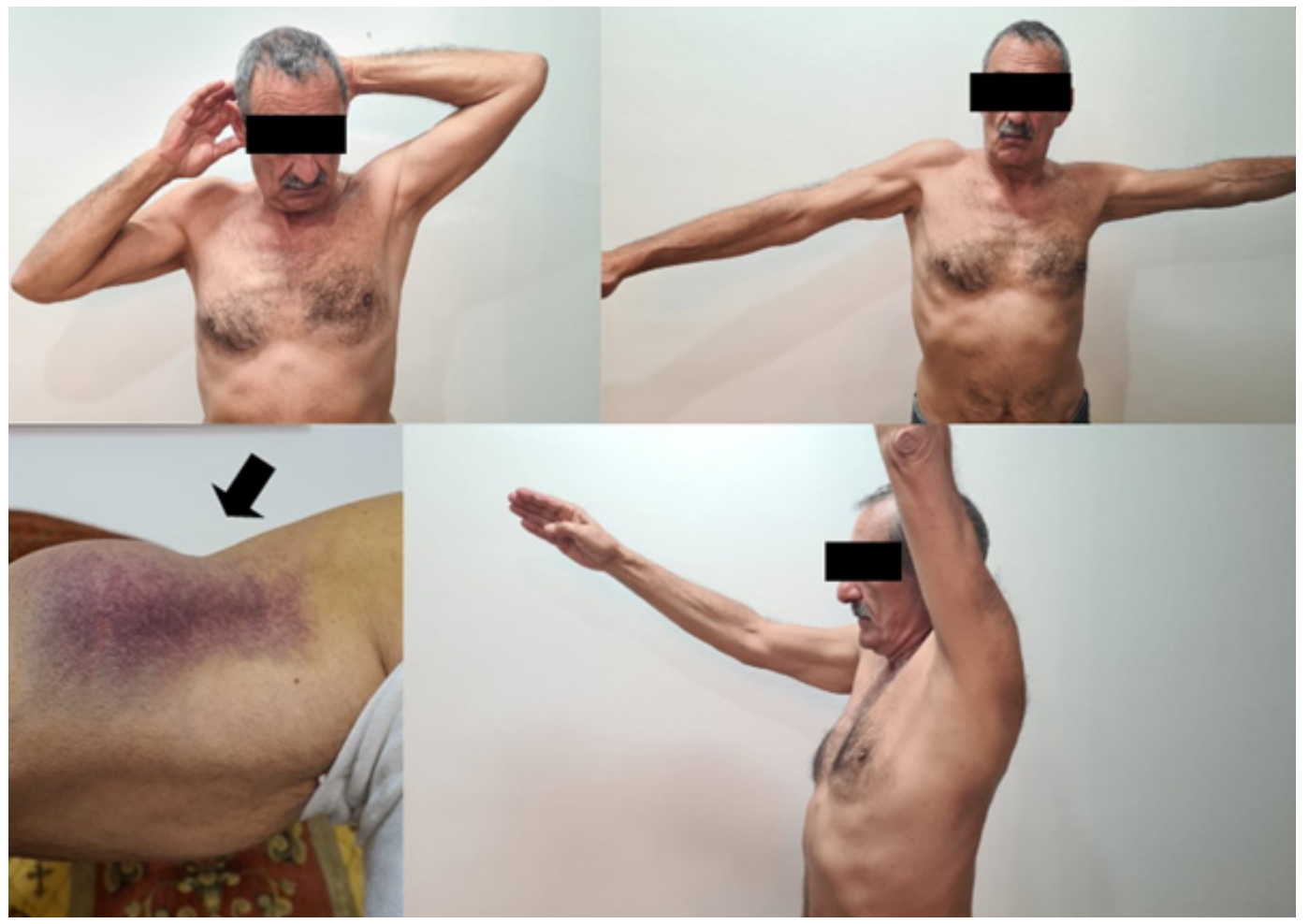

Figure 8: Limitation of ROM of right shoulder, Popeye's sign (black arrow).

\section{Discussion}

Coronaviruses (CoVs) mainly affects respiratory tract. In the past an epidemic disease was caused by Severe Acute Respiratory Syndrome (SARS-Cov) and Middle East Respiratory Syndrome (MERS-Cov) and it has severely endangered public health [13]. Patients with Covid-19 primarily develop fever and lung symptoms, which can quickly evolve into an acute respiratory distress syndrome, necessitating of intubation, ventilation and admission in intensive therapy unit. However, although Covid-19 is a major problem, people have continued to suffer from other diseases [14].

Patients usually are afraid to be infected in the hospital by the Covid-19 and for this reason a large number of outpatients visits and surgical procedures have been cancelled [15].

In addition, Covid-19 pandemic determined the complete cessation of elective orthopaedic surgery and the orthopaedic surgeons have been dedicated only to traumatic surgery. For example, in the Galeazzi Orthopaedic Institute in Milan, Italy, the number of specialist visits reduced to 239 in April 2020 compared to 8461 carried out in the same period in 2019 [16]. In line with this, Chang et al. [17] reported that only 56,8\% of patients confirmed the planned orthopaedic surgical care despite Covid-19 risk. Another important issue to consider is the impact of Covid-19 on rehabilitation of patients, which is an essential to improve the final outcome of orthopaedic surgery. Boldrini et al. [18] have shown that the two main problems, consequences of Covid-19, are the increasing pressure to transfer patients to rehabilitation unit with the aim to facilitate new admissions of Covid-19 cases and the increasing difficulties in providing rehabilitation care of home-based patients because of the local and national government restrictions.

This case series is not a mere description of the possible complications following orthopaedic surgical care in the Covidera. Conversely, this paper aims to analyse the consequences of Covid-19, on orthopaedic patients waiting for surgery or after surgery when they should undergo rehabilitation treatment.

There are some considerations that need to be discussed: first of all, our hospital is the main hub for treatment of Covid-19 patients in the area of Messina (Sicily, Southern Italy). This may explain the fear of patients in this area to be hospitalized unless in danger of life. It is desirable that patients will change their attitude towards virus as more is learned about and after a significant acceleration of the vaccination campaign. Finally, the cases presented belong to waiting list of only one surgeon (D.L.), and only iconic cases were selected for the report.

\section{Conclusion}

This pandemic is unprecedented. Both the general population and health-care workers need clear guidance and information. Avoiding care for treatable conditions is another" side effect" of Covid-19 that can potentially cause a lot of troubles like the direct consequences of the pandemic, not only in orthopaedic surgery but in all medicine fields.

\section{References}

1. Cucinotta D, Vanelli M (2020) WHO Declares COVID-19 a Pandemic. Acta Bio-Medica Atenei Parm 91(1): 157-160. 
2. Setiati S, Azwar MK (2020) COVID-19 and Indonesia. Acta Medica Indones 52(1): 84-89.

3. Mukherjee K (2020) COVID-19 and lockdown: Insights from Mumbai. Indian J Public Health 64(Supplement): S168-171.

4. Gualano MR, Lo Moro G, Voglino G, Bert F, Siliquini R (2020) Effects of Covid-19 Lockdown on Mental Health and Sleep Disturbances in Italy. Int J Environ Res Public Health 17(13): 4779.

5. The Lancet (2020) India under COVID-19 lockdown. Lancet 395(10233) 1315.

6. Moris D, Schizas D (2020) Lockdown During COVID-19: The Greek Success. In Vivo 34(3 Suppl): 1695-1699.

7. Cauchemez S, Kiem CT, Paireau J, Rolland P, Fontanet A (2020) Lockdown impact on COVID-19 epidemics in regions across metropolitan France. Lancet 396(10257): 1068-1069.

8. Haider N, Osman AY, Gadzekpo A, Akipede GO, Asogun D, et al. (2020) Lockdown measures in response to COVID-19 in nine sub-Saharan African countries. BMJ Glob Health 5(10).

9. Lau H, Khosrawipour V, Kocbach P, Mikolajczyk A, Schubert J, et al. (2020) The positive impact of lockdown in Wuhan on containing the COVID-19 outbreak in China. J Travel Med 27(3).

10. COVIDSurg Collaborative (2020) Elective surgery cancellations due to the COVID-19 pandemic: global predictive modelling to inform surgical recovery plans. Br J Surg 107(11): 1440-1449.
11. COVID-19 Map (20201) Johns Hopkins Coronavirus Resource Center.

12. Yam M, Kang BJ, Chawla A, Zhang W, Way LG, et al. 92020) Cephalomedullary blade cut-ins: a poorly understood phenomenon. Arch Orthop Trauma Surg 140(12): 1939-1945.

13. Rothan HA, Byrareddy SN (2020) The epidemiology and pathogenesis of coronavirus disease (COVID-19) outbreak. J Autoimmun 109: 102433.

14. Papakonstantinou NA, Dedeilias P, Samiotis I, Argiriou M (2020) SARS-CoV-2, COVID-19 pandemic, 'coronawar'... oops; something was forgotten. Cardiovascular disease is still here! The collateral damage. J Card Surg 35(9): 2134-2136.

15. Pappas G, Kiriaze IJ, Giannakis P, Falagas ME (2009) Psychosocial consequences of infectious diseases. Clin Microbiol Infect Off Publ Eur Soc Clin Microbiol Infect Dis 15(8): 743-747.

16. Oussedik S, Zagra L, Shin GY, D’Apolito R, Haddad FS (2020) Reinstating elective orthopaedic surgery in the age of COVID-19. Bone Jt J 102-B(7): 807-810.

17. Chang J, Wignadasan W, Kontoghiorghe C, Kayani B, Singh S, et al. (2020) Restarting elective orthopaedic services during the COVID-19 pandemic: Do patients want to have surgery? Bone Jt Open 1(6): 267-271.

18. Boldrini P, Bernetti A, Fiore P, SIMFER Executive Committee, SIMFER Committee for International Affairs (2020) Impact of COVID-19 outbreak on rehabilitation services and physical and rehabilitation medicine physicians' activities in Italy. An official document of the Italian PRM Society (SIMFER). Eur J Phys Rehabil Med 56(3): 316-318. 